\title{
Characteristics of interactions between black shale and water
}

\author{
Xin $\mathrm{Liao}^{1}$, Kangji Wang ${ }^{1}$, Xiyong $\mathrm{Wu}^{1,2, *}$, Sixiang $\mathrm{Ling}^{1}$, Deping $\mathrm{Guo}^{3,4}$, and Yingwei $\mathrm{Xi}^{5}$ \\ ${ }^{1}$ Southwest Jiaotong University, Faculty of Geoscience and Environmental Engineering, 611756 \\ Chengdu city, China \\ ${ }^{2}$ Southwest Jiaotong University, MOE Key Laboratory of High-Speed Railway Engineering, 610031 \\ Chengdu city, China \\ ${ }^{3}$ Sichuan Railway Investment Group Co., LTD, 610093, Chengdu city, China \\ ${ }^{4}$ Beijing Jiaotong University, School of Civil Engineering, 100044, Beijing city, China \\ ${ }_{5}^{5}$ Sichuan Environmental Monitoring Center, 610091 Chengdu city, China
}

\begin{abstract}
Some geological engineering problems are caused by weathering of black shale within dispersed sulfide minerals (mainly pyrite), in which some weathering products such as acid water and expansive sulfates play an important role. These effects are essentially manifested through oxidation of sulfide minerals. Complex chemical reactions occur simultaneously and influence mutually in water-rock interaction process. Chemical weathering of black shale is a factor leading to engineering problems such as landslides and acid corrosion. The objectives of present study are to understand the process of water-rock interactions between black shale and water. The semi-immersion simulation experiment is mainly used to explore the chemical weathering characteristics of black shale under natural conditions.
\end{abstract}

\section{Introduction}

Black shale interacts closely with environmental water, where sulfide minerals are highly sensitive to oxidizing environments and tend to form acidic products during oxidation. Acidic water will accelerate the dissolution of carbonates and silicate minerals, causing destruction to rocks. The predecessors carried out a large number of indoor model experiments to analyze the characteristics of water-rock interaction. By simulating the water-rock interaction between solution and sandstone in a specific environment, the mechanism of the influence of these chemical reactions on the porosity and permeability of the rock mass is proposed by Shiraki [1]. Chemical weathering of black shale was analyzed by immersion experiment using crushed rock samples by $\mathrm{Wu}$ [2]. The leaching experiment conducted by Bai was used to analyze the changes in physical properties of the rock mass and the chemical reaction between the infiltrated acidic water and rock [3]. Based on the physicochemical properties, microscopic morphological characteristics and formation conditions of weathering products of black shale, this paper combines field investigation and indoor immersion experiment to focus on the chemical weathering behavior of black

\footnotetext{
* Corresponding author: wuxiyong@ @ swjtu.edu.cn
} 
shale with water and oxygen.

The study site is in Sanjiang County, Guangxi Province of China, which is a hilly area. Black shale samples from the Cambrian Qingxi Formation were taken at the outcrop of a slope toe (Fig. 1). And fissure water samples were collected adjacent to black shales.

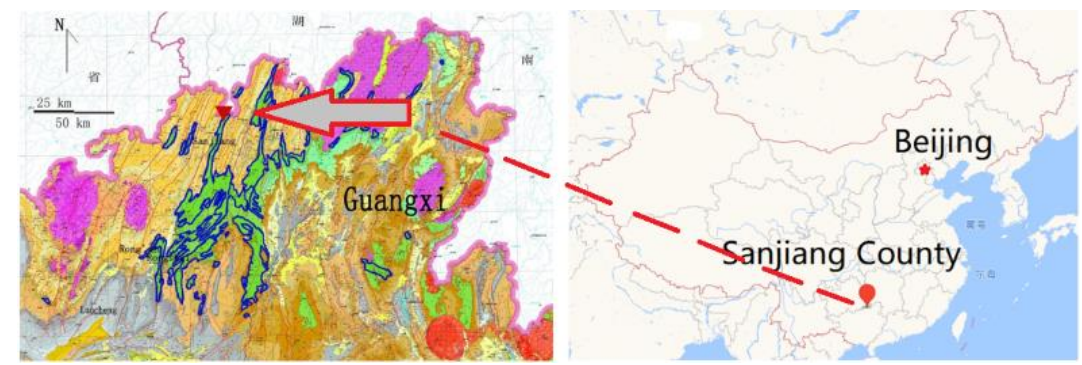

Fig. 1. Distribution of Cambrian Qingxi Formation black shale (green area) in Guangxi and sampling location (red inverted triangle).

\section{Mineral and water properties}

\subsection{Mineral components}

The mineral analysis results determined by XRD (X-ray diffraction) are shown in Table 1, which indicated that the black shale samples consisted mainly of quartz and illite. Meanwhile, the jarosite was also found in the rock samples.

Table 1. Major mineral contents of black shales (wt. \%).

\begin{tabular}{|c|c|c|c|c|c|c|c|c|c|c|c|}
\hline Sample & Q & Pla & Cal & Dol & Ill & Mu & Sm & Gyp & Py & Lim & Jar \\
\hline F1 & 73.7 & -- & -- & -- & 25.2 & -- & -- & -- & -- & -- & 1.0 \\
\hline F2 & 83.8 & -- & -- & -- & 14.1 & -- & -- & -- & -- & -- & 1.9 \\
\hline
\end{tabular}

Q: Quartz; Pla: Plagioclase; Cal: Calcite; Dol: Dolomite; Ill: Illite; Mu: Muscovite; Sm: Smectite; Gyp: Gypsum; Py: Pyrite; Lim: Limonite; Jar: Jarosite. - Non-detectible.

\subsection{Hydrochemical analyses}

The results of hydrochemical analyses of fissure water are summarized in Table 2. The major cations of the water samples were $\mathrm{Fe}^{2+/ 3+}(1370$ and $678 \mathrm{mg} / \mathrm{L}), \mathrm{Ca}^{2+}(114$ and 51.6 $\mathrm{mg} / \mathrm{L}$ ) and $\mathrm{Mg}^{2+}\left(265\right.$ and $33.4 \mathrm{mg} / \mathrm{L}$ ), while the anion was mainly $\mathrm{SO}_{4}{ }^{2-}$ (5980 and 2230 $\mathrm{mg} / \mathrm{L}$ ). The $\mathrm{pH}$ values of water samples are 2.5 and 2.4 , indicating strong acidity. The water samples had a relatively higher content of total $\mathrm{Fe}, \mathrm{SO}_{4}{ }^{2-}$ and $\mathrm{H}^{+}$, which indicates that the oxidation of pyrite has a significant impact on the $\mathrm{pH}$ of fissure water in the black shale areas.

Table 2. Chemical compositions of water samples ( $\mathrm{mg} / \mathrm{L})$.

\begin{tabular}{|c|c|c|c|c|c|c|c|c|c|c|}
\hline Sample & $\mathbf{C l}^{-}$ & $\mathbf{S O}_{4}{ }^{2-}$ & $\mathbf{S i O}_{\mathbf{2}}$ & $\mathbf{C a}^{2+}$ & $\mathbf{M g}^{2+}$ & $\mathbf{K}^{+}$ & $\mathbf{N a}^{+}$ & $\mathbf{A l}^{3+}$ & $\mathbf{T o t a l ~} \mathbf{~ F e}$ & $\mathbf{p H}$ \\
\hline $\mathrm{W} 1$ & $<2$ & 5980 & 99.5 & 114 & 265 & 1.11 & 0.61 & 377 & 1370 & 2.5 \\
\hline $\mathrm{W} 2$ & $<2$ & 2230 & 32.4 & 51.6 & 33.4 & 1.15 & 0.39 & 69.3 & 678 & 2.4 \\
\hline
\end{tabular}




\section{Semi-immersion experiment}

Under natural conditions, the rock mass on the surface of the earth mainly exists in a dry and wet alternating state. In order to study the characteristic of black shale interacting with water and oxygen, this paper used two black shale samples (F1 and F2) with similar degree of weathering to conduct indoor semi-immersion experiment. Half of the rock sample was immersed in deionized water and half was exposed to the air, which means part of the rock mass was above the water surface exposed to air oxidation and the part below undergoing liquid phase oxidation.

In the first ten days of the experiment, there was no significant change in the apparent appearance of black shale F1, and the color of the immersion solution did not change significantly (Fig. 2). As time passed, there were clear yellow particles on the 60th day. On the 114th day, weathering particles precipitated on the top surface were collected for XRD analysis. The result showed that the yellow particles were mainly copiapite (Eq.5-6), and the white particles were not detected due to the low content. They gradually aggregated in the middle of the upper part, forming a strip cover with yellow copiapite inside and white particles on the outer ring on the 218th day. The thickness of copiapite on the rock sample surface is about 1 to $2 \mathrm{~mm}$, and $\mathrm{pH}$ of water solution is about 2.4. After the solution in the vessel has completely evaporated, a yellow-brown granular precipitate can be seen at the bottom of the vessel.

Fig. 3 shows the typical phenomenon of black shale F2 interacted with water and oxygen within 139 days. On the 7th day, white granular minerals appeared in the middle area at the top of the rock sample and the color gradually became shallower from the outside to the middle. On the 54th day, white precipitates distributed on the top surface were collected and analyzed by XRD, which was proved to be rozenite (Eq.4). Yellow precipitates were observed and mixed with the white rozenite on the 139th day, which were examined to be copiapite. The $\mathrm{pH}$ of solution turned to be 2.2 .
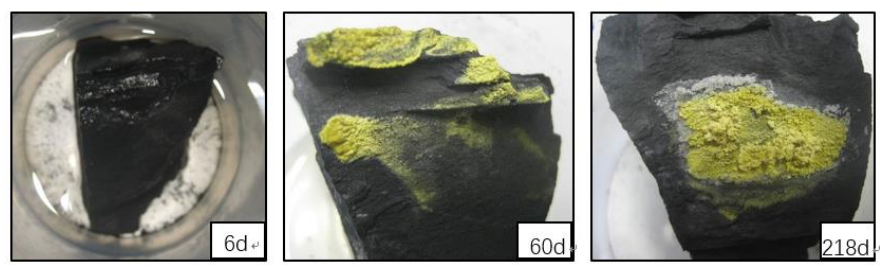

Fig. 2. Semi-immersion experiment of rock sample F1.
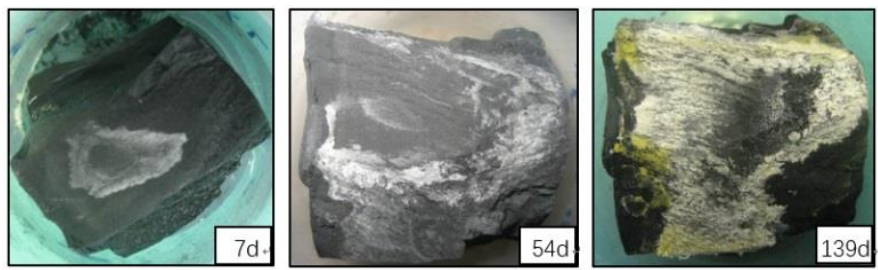

Fig. 3. Semi-immersion experiment of rock sample F2.

What's more, it can be seen that the number, size and diameter of the pores above the water table were significantly smaller than those below the water surface, and the distribution was relatively dispersive (Fig. 4). This phenomenon indicates that the mineral dissolution and transportation mainly occur in the immersed area in the water-rock interaction. It is speculated that the main reaction process in the underwater part is that the acidic oxidative dissolution of minerals will migrate upward with the capillary water force. 


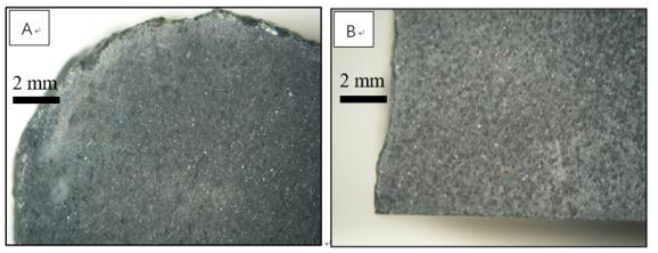

Fig. 4. Comparison of pore morphology between upper and lower part of rock sample after experiment (A and B are upper and lower parts of rock sample F2, respectively).

\section{Results and Discussions}

\subsection{Microscopic morphological characteristics}

Electron microscope and SEM were used to analyze the microscopic characteristics of the weathering products precipitated on the surface of the black shales in the semi-immersion experiment. The yellow precipitate aggregated on the surface of the sample F1 are composed of a large number of spherical particles, which are densely distributed and concentrated (Fig. 5A). The size of particles ranges from 0.1 to $1.8 \mathrm{~mm}$ and the diameter of those in the middle position is relatively larger. The transparent particles are distributed surrounded by the yellow precipitates. Under the SEM observation, most of yellow precipitates are spherical or ellipsoidal with smooth surfaces, and a few irregular cracks on the surface (Fig. 5B) [4].

The yellow precipitates are centered around the edge of the surface of the rock sample F2. The size is much smaller than that of the yellow precipitates of sample F1. The visual average size is less than $0.1 \mathrm{~mm}$ in Fig. 5C. The white precipitate is widely distributed in the middle part of rock surface. Good crystallization is similar to the oblique hexahedron, while others are almost fine particles bonded to each other, with many tiny pores can be seen in Fig. 5D.
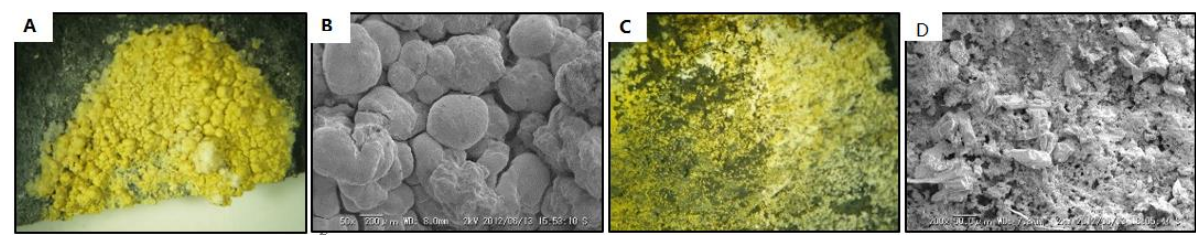

Fig. 5. Microscopic morphology of minerals precipitated from rock sample F1 and F2.

\subsection{Characteristics of $\mathrm{pH}$ and $\mathrm{EC}$ value of immersion solution}

The $\mathrm{pH}$ and electrical conductivity (EC) values of the immersing solution were measured daily. The measurement results show that the immersing solution is strongly acidic. The value of $\mathrm{pH}$ is between 2.2 and 4.0, and the value of $\mathrm{EC}$ is between 0.09 and $1.63 \mathrm{~ms} / \mathrm{cm}$. According to the correlation analysis, the two parameters show an exponential relationship in the immersing process (Fig. 6). It is speculated that on one hand, the concentration of hydrogen ions and EC values increase simultaneously due to the evaporation of water. On the other hand, the increase in hydrogen ions generated by the continuous oxidation of pyrite causes the clay minerals in the rock to dissolve, which can generate more soluble ions and increase the EC values. 


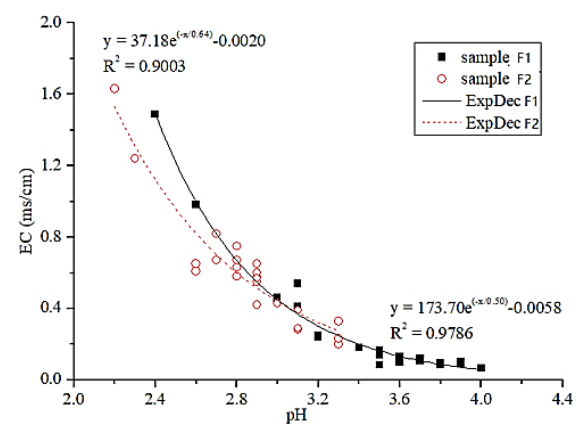

Fig. 6. pH-EC curve of immersing solution.

\subsection{Weathering products formation}

Various types of sulfate minerals can be formed by the oxidation of pyrite under different environmental conditions $[5,6]$. Combined with the characteristics of the weathering products of black shale in the field investigation and semi-immersion experiment indoor, it can be found that the sulfate minerals produced by pyrite oxidation have certain sequence characteristics. In semi-immersion experiment, the copiapite and rozenite are the paragenesis weathering products at early weathering stage, which are generated in a strongly acidic environment and mainly distributed along the surface cracks of the rock mass. The main relevant chemical reaction equations are as follows:

Pyrite oxidation process:

$$
\begin{aligned}
& \mathrm{FeS}_{2}+7 / 2 \mathrm{O}_{2}+\mathrm{H}_{2} \mathrm{O} \rightarrow \mathrm{Fe}^{2+}+2 \mathrm{SO}_{4}^{2-}+2 \mathrm{H}^{+} \\
& \mathrm{FeS}_{2}+15 / 4 \mathrm{O}_{2}+7 / 2 \mathrm{H}_{2} \mathrm{O} \rightarrow \mathrm{Fe}(\mathrm{OH})_{3}+2 \mathrm{SO}_{4}^{2-}+4 \mathrm{H}^{+} \\
& \mathrm{FeS}_{2}+14 \mathrm{Fe}^{3+}+\mathrm{H}_{2} \mathrm{O} \rightarrow 15 \mathrm{Fe}^{2+}+2 \mathrm{SO}_{4}^{2-}+16 \mathrm{H}^{+}
\end{aligned}
$$

Formation process of rozenite:

$$
\mathrm{Fe}^{2+}+\mathrm{SO}_{4}{ }^{2-}+4 \mathrm{H}_{2} \mathrm{O} \rightarrow \mathrm{FeSO}_{4} \cdot 4 \mathrm{H}_{2} \mathrm{O}
$$

The process of transforming rozenite into copiapite:

$$
5 \mathrm{FeSO}_{4} \cdot 4 \mathrm{H}_{2} \mathrm{O}+\mathrm{O}_{2}+\mathrm{H}_{2} \mathrm{SO}_{4} \rightarrow \mathrm{Fe}^{2+} \mathrm{Fe}^{3+}\left(\mathrm{SO}_{4}\right)_{6}(\mathrm{OH})_{2} \cdot 2 \mathrm{OH}_{2} \mathrm{O}
$$

Formation process of copiapite:

$$
5 \mathrm{FeSO}_{4}+\mathrm{O}_{2}+\mathrm{H}_{2} \mathrm{SO}_{4}+2 \mathrm{OH}_{2} \mathrm{O} \rightarrow \mathrm{Fe}^{2+} \mathrm{Fe}^{3+}\left(\mathrm{SO}_{4}\right)_{6}(\mathrm{OH})_{2} \cdot 2 \mathrm{OH}_{2} \mathrm{O}
$$

\section{Conclusions}

In this paper, characteristics of interactions between black shale and water are studied through field investigation and indoor semi-immersion experiment. Pyrite oxidation plays an important role in acid solution and various sulfate weathering products generation. The correlation between $\mathrm{pH}$ and $\mathrm{EC}$ values is manifested in an exponential relationship. Various sulfate weathering products show a certain sequence at different weathering stages.

This study was supported by the National Natural Science Foundation of China (Project Nos. 41472256, 41877215, 41502269) and the Fundamental Research Funds for the Central Universities 
(Project No. 2682017CX078).

\section{References}

1. R. Shiraki, T.L. Dunn, Appl. Geochem. J. 15, 265-279 (2000)

2. X. Wu, S. Ling, Y. Ren, X. Liao, et al. Earth Science. J. 41, 218-233 (2016)

3. G. Bai, B. Liang, X. Tang, Journal of Liaoning Technical University. J. 28, 162-164 (2009)

4. I.M. Farkas, T.G. Weiszburg, P. Pekker, et al. Can Mineral. J. 47, 509-524 (2009)

5. X. Liao, X. Wu, B. Zhu, Journal of Central South University. J. 44, 4980-4987 (2013)

6. C.O. Moses, D.K. Nordstrom, J.S. Herman, A.L. Mills, Geochimica et Cosmochimica Acta. J. 51, 1561-1571(1987) 